\title{
GESTÃO DE DESIGN PARA SUSTENTABILIDADE COM BASE NA POLÍTICA NACIONAL DE RESÍDUOS SÓLIDOS: uma proposta de integração
}

\author{
Ricardo Goulart Tredezini Straioto, Msc. \\ Univesidade Federal de Santa Catarina \\ ricardo.straioto@gmail.com \\ Luiz Fernando Gonçalves Figueiredo, Dr. \\ Univesidade Federal de Santa Catarina \\ 1ffigueiredo2009@gmail.com
}

\begin{abstract}
Resumo: No Brasil, com a aprovação da Lei 12.305/2010 que institui a Política Nacional de Resíduos Sólidos, vários princípios, objetivos e instrumentos foram definidos para reduzir os impactos a saúde e a qualidade ambiental decorrentes do ciclo de vida dos produtos produzidos e/ou consumidos no território nacional. Frente a esse contexto, este artigo teve como objetivo apresentar a proposição de um modelo de Gestão de Design com base na Política Nacional de Resíduos Sólidos. A partir de uma pesquisa teórica exploratória, foi proposta uma integração entre os níveis estratégico, tático e operacional de gestão de design com os parâmetros identificados na Lei. Como resultado obtivemos a gestão estratégica de design para sustentabilidade, a gestão tática de design participativo e a gestão operacional de design de sistemas sustentáveis.
\end{abstract}

Palavras-chave: Gestão de Design, Sustentabilidade, Brasil, Resíduos Sólidos

\begin{abstract}
In Brazil, with the approval of Law 12.305/2010, establishing the Solid Waste National Policy, a number of principles, objectives and instruments were set to reduce the impacts on health and environmental quality resulting from the life cycle of products produced and / or consumed in the country. In this context, this paper aims to present a proposition of a design management model based in the Solid Waste National Policy. From an exploratory theoretical research, it proposes an integration between the strategic, tactical and operational levels of design management and the parameters identified in the Law. As a result we obtained: a strategic management of design for sustainability, tactical management of participatory design and operational management of sustainable systems design.
\end{abstract}

Key-words: Design Management; Sustainability; Brazil; Solid Waste

\section{INTRODUÇÃO}

Desde a aprovação da Lei 12.305, em agosto de 2010, que instituiu a Política Nacional de Resíduos de Sólidos (PNRS) que pesquisas são desenvolvidas sobre a Lei e suas implicações para o design de produtos ou serviços. O interesse é justificável frente 
aproximação natural entre as pesquisas sobre Design de Ciclo de Vida do Produto e temas tratados na lei, como a Responsabilidade Compartilhada pelo Ciclo de Vida do Produto, ou mesmo de instrumentos como a Logística Reversa (art.8, inciso III).

Straioto e Figueiredo (2011), em artigo sobre as perspectivas para o Design sustentável no Brasil a partir da nova Política Nacional de Resíduos Sólidos, tecem considerações pertinentes a proposta deste artigo. Mesmo tratando-se de uma Política de Gestão de Resíduos, a questão pode ser vista como estratégica para o design. Tendo como premissa que é mais oportuno e ecoeficiente nos dedicarmos a projetar produtos mais sustentáveis, do que apenas buscarmos soluções para os danos já causados ao ambiente. A partir deste contexto, um cenário promissor pode ser vislumbrado. Neste cenário devemos observar um aumento da demanda no mercado nacional, por parte das indústrias e demais agentes econômicos, por profissionais capazes de desenvolver políticas, estratégias e produtos que incluam os parâmetros fornecidos pela lei, como por exemplo a abordagem do ciclo de vida do produto. As empresas são "estimuladas" pela PNRS a adotarem padrões de produção e consumo sustentáveis. Neste sentido são necessários conhecimentos, métodos e técnicas adequados aos profissionais das organizações que operam no território nacional satisfazendo a demanda por produtos e serviços mais sustentáveis. Neste caso, o design para sustentabilidade, seu objetivo, suas ferramentas e métodos são muito úteis para a empresa melhorar sua ecoeficiência.

Frente ao cenário apresentado, este artigo tem como objetivo dar continuidade ao debate sobre as aproximações e implicações da Lei para atividade de design dentro das organizações, o que na visão dos autores do presente artigo deve valorizar a área de Gestão de Design nas empresas e indústrias.

Desse modo o artigo busca propor um modelo de Gestão de Design baseado nos princípios, objetivos e instrumentos instituídos pela PNRS. As definições e dados gerais que contextualizam o alcance da lei 12.305/2010 sobre a economia, a saúde e ao meio ambiente não fazem parte do escopo deste artigo, pois já foi traçado um panorama geral por Straioto e Figueiredo (2011). Desse modo podemos considerar este artigo, em parte, como uma continuidade do debate já iniciado, contudo aproximando a discussão com a área de Gestão do Design.

\subsection{Metodologias e procedimentos da pesquisa}

Para a construção da proposta de integração da Política Nacional de Resíduos Sólidos e Gestão de Design, foram empregadas a pesquisa teórica e documental, de natureza qualitativa e caráter exploratório. A pesquisa documental teve o intuito de definir os parâmetros relevantes da Política Nacional de Resíduos Sólidos para sua integração com a Gestão de Design, considerou como documento a Lei 12.305/2010.

A pesquisa teórica, segundo Martins (2000), tem como objetivo conhecer as contribuições científicas sobre determinado assunto. Visa recolher, selecionar, analisar e intepretar as contribuições sobre Gestão de Design nos níveis: operacional, tático e 
estratégico. E também pesquisar sobre as abordagens de design identificadas para cada nível de gestão como compatíveis com a PNRS.

Segundo Gil (1987), o caráter exploratório de uma pesquisa é pertinente quando se desenvolve, esclarece e modifica conceitos e ideias, com vistas à formulação de problemas mais precisos ou hipóteses para estudos posteriores. A pesquisa adquire este caráter pois o resultado da pesquisa limita-se a ser uma proposta de integração entre os temas. Sendo uma hipótese construída por meio de raciocínio indutivo, a partir da análise da Lei 12.305/2010 e a subsequente pesquisa por teorias e métodos de design que atendam aos parâmetros identificados.

O artigo está estruturado partindo da revisão da literatura sobre Gestão de Design em seus três níveis. Em seguida, apresenta-se o modelo de Gestão de Design para Sustentabilidade, propondo abordagens de design consideradas compátiveis com cada nível de gestão de design e os parâmetros selecionados da Política Nacional de Resíduos Sólidos. Por fim, um visão geral sobre as abordagens de design propostas, sendo elas: a gestão estratégica do design para sustentabilidade, a gestão tática do desgin participativo e a gestão operacional do design de sistemas sustentáveis.

\section{GESTÃO DE DESIGN}

Graças ao nível sem precedentes de empresas atuando no mercado, a inovação ganha lugar como uma estratégia poderosa no mundo dos negócios. O fato é que, se é preciso inovar, tem-se de adotar o design. (NEUMEIR, 2010)

Esta crescente necessidade de inovação imposta às organizações que concorrem em mercados cada vez mais dinâmicos, elevou o design a níveis estratégicos dentro das organizações, fomentando a área da Gestão de Design, que visa, principalmente, a incorporação da inovação em produtos e serviços, bem como, nos processos operacionais e na cultura da organização. (CPD , 1997)

Uma definição de gestão de design provém do DMI(2014): A gestão de design abrange os processos, as decisões e estratégias que permitem que a inovação e a criação de produtos, serviços, comunicações, ambientes e marcas projetados de forma eficaz, que melhorem a qualidade de vida e proporcione o sucesso organizacional.

No escopo da aplicação da Gestão de Design, serão utilizados os três níveis de tomada de decisão apresentados Mozota (2011, p.227):

- O nível estratégico, ou o papel do design para unificar e transformar a visão da empresa, pode designar a gestão de uma empresa de acordo com princípios e estratégias de design;

- O nível tático (funcional), ou a criação de uma função de design na empresa pode referir-se a administração de um departamento de design (ou mesmo de uma empresa de design) e a coordenação do processo de inovação;

- O nível operacional do projeto, geralmente o primeiro passo para a integração do design a empresa e pode referir-se a gestão de um projeto de Design.

\subsection{Gestão Estratégica de Design: missão e visão}


A Gestão Estratégica do Design inclui a defesa estratégica do design em toda a organização como um diferenciador-chave e condutor de sucesso, a partir do uso de uma filosofia de design na gestão organizacional, ou seja, usar o processo de design para resolver os problemas gerais da organização (DMI, 2014). A Gestão de Design no nível estratégico da organização atua realizando diagnósticos situacionais, definindo campos de atuação, fazendo do design e da inovação algo instalado na cultura organizacional (CPD, 1997).

Segundo Mozota (2011), neste nível o design age como transformador da própria empresa, antecipando uma visão clara dos futuros mercados e da concorrência, criando novos mercados e prevendo tendências. Podendo ter efeito direto sobre o posicionamento da organização, contribuindo para a gestão da mudança e para o processo de aprendizagem nas organizações. O objetivo é controlar a coerência da atividade de design na organização e inserir o design em um processo de formulação estratégica, definindo uma estratégia empresarial que incorpore metas de design, levando o design para a missão empresarial.

Para gerar uma cultura de inovação constante na empresa é preciso um sistema de treinamento constante, isto é, um tipo de educação customizada para a marca, cultura e missão da empresa. Esse treinamento explora os modos como os funcionários constroem o valor da marca, como auxiliam na conquista do cliente, como alinham suas ações individuais à estratégia geral da empresa. Ao incorporar o pensamento focado no design em uma visão ou mesmo na missão da empresa, busca-se gerar um leque ampliado de opções. Desse modo, a empresa projeta o caminho à frente, em lugar de simplesmente escolhê-lo. (NEUMEIR, 2010)

\subsection{Gestão Tática de Design: função}

A gestão tática de design refere-se a função design na organização e agências de design, incluindo a coordenação das operações de design, pessoal, métodos e processos (DMI, 2014). Nesta área da gestão do design, a natureza do design muda: não mais um produto ou objeto, o design torna-se uma função ou departamento dentro da organização, participando ativamente do sucesso da empresa no mercado. Atuando como coordenador do processo de inovação, agindo como uma ferramenta eficiente na gestão do desenvolvimento do novo produto. Ajudando a coordenar funções, motivar e melhorar a comunicação em uma equipe de projeto. Ligando-se à gestão de processos da organização e à gestão da inovação. (MOZOTA, 2011)

A Gestão funcional do design tem como objetivo definir a estratégia de design em relação à estratégia da organização, assim como promover a "educação" de outros departamentos em métodos de criatividade em design por meio de programas que possam ser aplicados a todas as funções. Além disso, deve inserir a estratégia de design na implementação da estratégia organizacional, criar uma estrutura para inovação e projetos (instituindo um departamento de design interno), organizar as comunicações internas e externas sobre design cultivando a compreensão do design entre parceiros e colaboradores, analisar o processo de design e melhorá-lo. (MOZOTA, 2011) 
Como é impossível mecanizar a criatividade e leva-la para linha de produção, Neumeir (2010, p.138) aponta que, "o melhor a fazer é construir uma compreensão compartilhada dos princípios do design para que todas as pessoas na empresa tenham chance de experimentar, aprender e crescer em equipe".

\subsection{Gestão Operacional de Design: diferenciação}

A gestão de design em um nível operacional é, em suma, o nível com a responsabilidade da implementação das novas ideias (CPD, 1997). Aqui, o design atua como elemento diferenciador, dentro de uma estratégia de produto que diferencie a empresa da concorrência e fortaleça sua vantagem competitiva. O estabelecimento da marca é o processo de diferenciação mais empregado. A diferenciação e o gerenciamento da marca são parte da gestão do design. A gestão operacional de design é a gestão de um projeto de design que visa aprimorar o produto, a embalagem ou o desempenho do serviço, incrementado as vendas e o valor percebido. Neste nível cabe a definição da política de design dentro das políticas de comunicação e do produto, a administração do orçamento do projeto de design. (MOZOTA, 2011)

A maioria das organizações utiliza o design apenas em seu nível operacional, para gerar uma série interminável de materiais de uso cotidiano, como produtos, comunicados impressos, websites, sinalizações, ambientes de varejo, embalagens, expositores para eventos comerciais, publicidade, manuais, relatórios financeiros, etc. Porém, ao desenvolver os níveis táticos e estratégicos é possível somar a esses produtos uma lista de novas oportunidades, como experiências com cliente, design de serviços, processos operacionais, treinamentos de marca, design organizacional, tomada de decisão, estratégia de negócios e liderança de pensamento - nesse momento passa a ser importante ter uma Gestão de Design forte dentro da organização. (NEUMEIR, 2010, p.98)

\section{PROPOSTA DE GESTÃO DE DESIGN PARA SUSTENTABILIDADE}

Frente ao desafio da sustentabilidade os governos, empresas, instituições, comunidades e cidadãos, mesmo cientes do seu caráter essencialmente transnacional, cada um deve esforçar-se em ações locais que facilitem e estimulem a transição para padrões de produção e consumo sustentáveis.

No Brasil, a política ambiental é dividida em agenda verde, azul e marrom. Na agenda verde - área de florestas - um dos projetos mais importantes até o momento foi o que definiu o Sistema Nacional de Unidades de Conservação (SNUC). Na agenda azul, que trata da água, fixou-se a base legal para preservar os recursos hídricos. A agenda marrom é muito ampla e um dos seus pontos essências foi o debate sobre resíduos sólidos. (GABEIRA, 2003)

Fruto de um debate que se estendeu por duas décadas, em 02 de agosto de 2010 foi sancionada a Lei 12.305 que institui a Política Nacional de Resíduos Sólidos. A Lei $12.305 / 2010$, estabelece princípios, objetivos e instrumentos para a gestão dos resíduos sólidos, sendo que suas consequências incluem a saúde pública, a 
preservação ambiental, além do caráter econômico. Pois responsabiliza toda cadeia produtiva de um produto, incluindo fornecedores de matéria prima, indústrias, distribuidores, comerciantes e consumidores.

Uma análise da lei quanto a economia de recursos e geração de renda para cooperativas e indústrias de reciclagem dos diversos materiais, os acordos setoriais realizados entre governo e setores da indústria, e também uma apresentação geral sobre os principios, objetivos, intrumentos da PNRS pode ser encontrada em Straioto e Figueiredo (2001), além de uma primeira aproximação sobre os desafios e implicações para o Design. O presente artigo visa dar continuidade as pesquisas ao propor um modelo de Gestão de Design coerente com a Política Nacional de Resíduos Sólidos.

A partir dos parâmetros destacados no Quadro 1, buscou-se articulá-los com os três níveis de Gestão de Design. A proposta de integração resultou em um modelo conceitual de Gestão de Design adequado ao parâmetros da PNRS. Em seguida, passaremos aos fundamentos básicos das abordagens de design proposta no modelo.

Quadro 1 - Proposta de integração da PNRS com a Gestão de Design

\begin{tabular}{|c|c|c|}
\hline $\begin{array}{l}\text { Níveis de Gestão } \\
\text { de Design }\end{array}$ & $\begin{array}{l}\text { Parâmetros Política Nacional de Resíduos } \\
\text { Sólidos (Lei } 12.305 / 2010 \text { ) }\end{array}$ & $\begin{array}{l}\text { Abordagem de Design } \\
\text { Compatível }\end{array}$ \\
\hline $\begin{array}{l}\text { Gestão Estratégica: } \\
\text { Transformação da visão e } \\
\text { do posicionamento da } \\
\text { empresa; } \\
\text { Design na missão e como } \\
\text { filosofia de gestão }\end{array}$ & $\begin{array}{l}\text { - Desenvolvimento sustentável e estímulo } \\
\text { à adoção de padrões sustentáveis de } \\
\text { produção e consumo de bens e serviços } \\
\text { (art.7, inciso III); } \\
\text { - Visão sistêmica (art.6, inciso III); }\end{array}$ & $\begin{array}{l}\text { - Design para } \\
\text { Sustentabilidade; } \\
\text { - Design sistêmico }\end{array}$ \\
\hline $\begin{array}{l}\text { Gestão tática: } \\
\text { Coordenação da estrutura e } \\
\text { do processo de inovação; } \\
\text { Design nos métodos e } \\
\text { processos da empresa }\end{array}$ & $\begin{array}{l}\text {-Responsabilidade compartilhada pelo } \\
\text { ciclo de vida do produto (art.6, inciso VII); } \\
\text { - Controle Social (art.6, inciso X); } \\
\text { - Acordo Setorial (art.8, inciso XVI); } \\
\text {-Cooperação no desenvolvimento de } \\
\text { novos produtos, métodos, processos e } \\
\text { tecnologias. (art.8, inciso VI) }\end{array}$ & - Design Participativo \\
\hline $\begin{array}{l}\text { Gestão operacional: } \\
\text { o design na gestão do } \\
\text { projeto de diferenciação do } \\
\text { produto/serviço }\end{array}$ & $\begin{array}{l}\text { - Ciclo de vida do produto, (art.3, inciso } \\
\text { IV); } \\
\text { - Logística Reversa (art.8, inciso III); } \\
\text { - Adoção, desenvolvimento de tecnologias } \\
\text { limpas como forma de minimizar } \\
\text { impactos ambientais (art.7, inciso IV); }\end{array}$ & $\begin{array}{l}\text { Design do Ciclo de Vida do } \\
\text { Produto (Sistema de } \\
\text { Produto-Serviço) }\end{array}$ \\
\hline
\end{tabular}

Fonte: elaborado pelo autor, com base em pesquisa realizada em 2012.

\subsection{Gestão Estratégica do Design para Sustentabilidade}

Como resultado desta proposta de integração no nível de Gestão Estratégica de Design, os parâmetros da Lei considerados foram o princípio do desenvolvimento sustentável (art.7, inciso III) e da visão sistêmica (art.6, inciso III). O primeiro 
parâmetro, que inclui o objetivo do estímulo à adoção de padrões de sustentáveis de produção e consumo de bens e serviços, foi considerado como fator relevante para estabelecer a missão e o posicionamento empresa. O parâmetro da visão sistêmica, que deve considerar as variáveis ambiental, social, cultural, econômica, tecnológica e de saúde pública como referência para a transformação da visão da própria empresa. Lembrando que, neste nível estratégico o design atua como filosofia para a gestão da empresa, foram elencados como abordagens de design compatíveis o design para sustentabilidade, que define um objetivo e pode compor a missão da empresa, e o design sistêmico representa uma visão holística e integradora da realidade e compartilha de valores e princípios próprios.

\subsubsection{Design para sustentabilidade}

As primeiras abordagens que consideravam a dimensão ambiental dentro do design estavam centradas na redução do impacto ambiental de materiais e processos. Em seguida, o foco foi ampliado, buscando reduzir o impacto ambiental de todo o ciclo de vida do produto. A busca por soluções que ampliassem ainda mais o foco, integrando a dimensão ambiental, social e econômica, levou ao desenvolvimento do conceito de "design para sustentabilidade". Essa abordagem pode ser considerada uma visão estratégica da concepção e do desenvolvimento de soluções sustentáveis que possibilitam as pessoas viverem melhor, consumindo menos recursos ambientais e melhorando a qualidade de vida. (KRUCHEN, 2009)

Manzini e Vezzolli (2005, p.23) propõe o design para sustentabilidade, isto é, "promover a capacidade do sistema produtivo de responder à procura social por bemestar utilizando uma quantidade de recursos ambientais drasticamente inferior aos níveis atualmente praticados." Segundo os autores, o design para a sustentabilidade pode ser reconhecido como uma espécie de design estratégico, ou seja, o projeto de estratégias aplicadas pelas empresas que se impuseram seriamente a prospectiva da sustentabilidade ambiental. Assim, a contribuição do design na transição para sustentabilidade é promover o aparecimento de uma nova geração de produtos e serviços intrinsecamente mais sustentáveis. O que significa operar no duplo terreno do design para sustentabilidade e do design de ciclo de vida do produto.

Vezzolli (2010) considera que a visualização e avaliação da sustentabilidade de um produto devem partir da sua função, ao invés do produto físico em si. Desse modo, ao longo dos últimos anos, com uma interpretação mais correta da sustentabilidade, a atenção foi deslocada para uma dimensão maior do que o produto isolado, considerando o design para inovação de sistemas ecoeficientes. Nesse âmbito, pesquisadores em design têm se referido ao chamado Sistema de Produto-Serviço. Afinal, segundo Thackara (2008,p.34), pensar a eficiência radical de recursos significa considerar que os produtos são meios para um fim e não fins em si mesmos.

No debate para definir design e inovação de sistema, há convergência para a definição do Programa Ambiental das Nações Unidas, onde uma inovação de sistema (em referência ao Sistema de Produto-Serviço, PSS) é o "resultado de uma estratégia 
inovadora que desloca o centro dos negócios, do projeto e da venda de produtos isolados, para oferecer produtos e sistemas de serviços que, conjuntamente, podem satisfazer demandas específicas" (UNEP, 2002 apud VEZZOLLI, 2010).

\subsubsection{Design Sistêmico}

Para Portas (1993) um dos aspectos recentes da evolução da teoria do design é a consciência de que a concepção de um produto tem relação não só com a lógica econômica da fabricação e uso, mas também com sistemas que transcendem o produtor e o usuário individual, sistemas que sua utilidade social depende. Um produto é apenas um componente de um sistema, num sistema de sistemas. Pois a produção de um produto tem de ser objeto de um planejamento superior a que podemos chamar de controle social. Controle não só em relação às normas e leis, mas também em relação à prioridade da economia em relação à escassez de recursos, à distribuição social dos bens e ao equilíbrio ecológico do ambiente. Pensar os produtos em termos de sistemas significa que os produtos ou seus efeitos, uma vez consumidos em primeira instância, mantém seu valor econômico ou cultural e encontram outras possibilidades de utilização em vez de serem eliminados de forma poluidora.

Segundo Portas (1993) o designer sistêmico tem fatalmente de participar nas decisões de política da produção, até o momento exclusivas da alta administração, aplicando sua técnica e imaginação na procura de produtos mais necessários e inovadores. Sendo que o êxito deste designer depende dos feed-backs em relação aos programas de produção não do usuário individual, mas da comunidade organizadora.

A visão sistêmica no design é atualmente a uma das principais correntes para a concepção de produtos, serviços, processos e sistemas. Esta compreensão é corroborada pelas Diretrizes Curriculares Brasileiras do Curso de Graduação de Design, que em seu Art. 4으, inciso IV define a visão sistêmica de projeto como habilidade e competência de um profissional de design.

A "visão sistêmica", ou mesmo holística, que consiste em dar maior ênfase ao todo do que à parte. $O$ que permite a inclusão de aspectos importantes, como relacionamentos com o ambiente e com outros sistemas. Ou mesmo a mudança de foco dos objetos para as relações, da hierarquia para as redes, da causalidade para o ciclo, etc. Por fim, o pensamento sistêmico tem utilidade como técnica e como forma de pensar a respeito da realidade. (ANDRADE, 2006)

A visão sistêmica e objetivo de criar sistemas sustentáveis são componentes chaves em uma estratégia de gestão de design para sustentabilidade. De maneira geral, uma estratégia não é outra coisa senão o feito de integrar os diversos tipos de atores em uma "visão estratégica", ou seja, em um posicionamento que vai permitir que, através da contribuição e compartilhamento dos mesmos valores entre todos os atores envolvidos, se alcance a posição na qual os mesmos consideram que têm legitimidade. Onde a causa principal do fracasso das estratégias é consequência de uma falta de coesão em seus valores internos e, dominantemente, por uma incapacidade de comunicá-la, de forma que integre e envolva os diversos atores (ECHEVARRIA, 2006). 


\subsection{Gestão Tática do Design Participativo}

Na Gestão Tática de Design, para integrar e envolver os diversos atores, propõem-se a adoção do design participativo. Os parâmetros destacados que justificam a abordagem do design participativo foram: o princípio da responsabilidade compartilhada pelo ciclo de vida do produto (art.6, inciso VII) e seu principal instrumento de implementação, os acordos setoriais (art.8, inciso XVI). Assim, como o princípio do controle social (art.6, inciso X), que garante à sociedade a participação nos processos de formulação, implementação e avaliação das políticas públicas e, também, a Cooperação no desenvolvimento de novos produtos, métodos, processos e tecnologias (art.8, inciso VI) sobre as questões pertinentes a Lei.

Neste nível tático de gestão de design, o design está presente nos métodos e processos da empresa, além de coordenar a estrutura e o processo de inovação. Sendo assim, a abordagem do design participativo foi considerada compatível tanto pela participação social e cooperação apresentada nos parâmetros destacados da Lei, quanto devido a responsabilização dos fabricantes, importadores, distribuidores e comerciantes, dos consumidores e dos titulares dos serviços públicos sobre o impacto gerado pelo produto, e assim, tornando-se coerente envolvê-los no processo de design do próprio produto sob o qual serão responsabilizados.

\subsubsection{Design Participativo}

A abordagem participativa no design tem suas origens nos ideais de uma democracia participativa, onde a decisão coletiva é descentralizada, de modo que todos os indivíduos podem participar efetivamente das decisões que os afetam. A participação não é somente para fins de obtenção de um acordo. É também para envolver as pessoas na adaptação significativa e proposital para mudar a sua vida diária. (SANOFF, 2007)

Nesse contexto, Vezzolli (2010) argumenta que o design operaria como um facilitador e promotor de inovações de sistemas que resultariam em iniciativas/empreendimentos ecoeficientes e socialmente justos e coesos. Um ponto chave destas discussões é a abordagem do design sob a perspectiva da configuração dos atores envolvidos, com intuito de criar e promover formas de interação e de parcerias inovadoras entre atores. Dessa forma, requerendo do designer competências como facilitar processos de design participativo entre empreendedores, usuários, ONGs, instituições, entre outros, direcionando esse processo para soluções sustentáveis.

Há uma série de maneiras diferentes das organizações abordarem a inovação e o design, a seguir seguem uma abordagem que podem ser vistas como estágios de uma caminhada para a inovação e o design participativo. Segundo Stamm (2008) as abordagens parecem se cristalizar em torno de dois pontos fundamentais: a abordagem do processo (Design) e a abordagem das pessoas (Participativo). 
A abordagem do processo é frequentemente assumida pelas organizações como um estágio inicial no caminho da inovação, geralmente inicia-se na formalização de métodos de design, passando pelas etapas e técnicas utilizadas para conceber e materializar a inovação (KERNZER, 2006).

Stamm (2008) afirma que a criação de uma organização realmente inovadora requer uma abordagem centrada em pessoas, afinal de contas, são as pessoas que vêm com ideias e as transformam em inovações, não processos. Cabe ressaltar, que as pessoas podem promover a inovação no próprio processo, ou seja, promover a inovação no próprio sistema de gestão.

Assim, se a abordagem escolhida é das pessoas, Stamm (2008) indica opções, como: o campeão da inovação (desenvolvimento de novos produtos ao nível do projeto individual), a equipe da inovação (pequeno grupo de pessoas com a responsabilidade pela inovação), departamento central de inovação com embaixadores (grupo central de pessoas com representantes nos demais grupos que coordenam a inovação por toda a organização) e, por fim, a concepção holística da inovação (todos as pessoas estão comprometidas com a inovação).

As quatro opões também podem ser vistas como etapas em uma caminhada para inovação e para o trabalho em equipe.A escolha de cada uma destas opções se dará em virtude das circunstâncias específicas de cada empresa. De acordo com Kerzner (2006,p.460) “Em empresas de excelência, por meio do trabalho em equipe, funcionários e gerentes trocam idéias e estabelecem altos índices de inovação e criatividade nos grupos de trabalho."

\subsection{Gestão Operacional do Design de Sistemas Sustentáveis}

No nível operacional da Gestão de Design, que consiste na gestão dos projetos de design na empresa, um primeiro parâmetro é o ciclo de vida do produto (art.3, inciso (V), onde dentro da perspectiva do design para sustentabilidade e do design sistêmico, deve-se projetar o produto para além de suas características formais e funcionais, considerando a conjunto de relações que ele terá com seu ambiente durante todo o seu ciclo de vida. O que nos leva ao segundo parâmetro, o instrumento da logística reversa(art.8, inciso III), pois com o projeto de todo o ciclo de vida do produto - desde a extração da matéria-prima, escolha de materiais, produção, distribuição, consumo e descarte, torna-se mais fácil projetar a logística reversa, ou seja, o caminho de volta do produto. Seja enquanto resíduos para serem reaproveitados em seu ciclo (ciclo fechado) ou em outros ciclos produtivos, ou mesmo à outra destinação ambientalmente adequada.

Além disso, o mapeamento do conjunto de trocas que o produto realiza com o ambiente em todo o seu ciclo de vida facilita a conscientização do seu real impacto ambiental, com intuito de minimizá-lo. Dessa forma, relaciona-se com um dos objetivos da lei que fora selecionado: a adoção, desenvolvimento e aprimoramento de tecnologias limpas como forma de minimizar impactos ambientais (art.7, inciso IV). 
Para Manzini e Vezzoli (2005), o design assume uma abordagem sistêmica quando a tarefa de desenvolver um produto torna-se o ato de projetar todo o ciclo de vida do produto. Há também no design de ciclo de vida do sistema produto-serviço um caráter complementar ao Design para sustentabilidade. $\mathrm{O}$ design para sustentabilidade se estabelece no nível estratégico da gestão de design, pois realiza o projeto de estratégias para as empresas que tem como missão a sustentabilidade. $\mathrm{E}$ o design de ciclo de vida do produto como método e diretriz que serve como modelo para implementar as estratégias através dos projetos.

Além disso, o design centrado em produtos físicos vem evoluindo para uma perspectiva sistêmica, conforme aumentam à complexidade dos problemas, as soluções exigem uma visão abrangente de projeto, envolvendo produtos, serviços e comunicação de forma conjunta e sustentável. (KRUCHEN, 2009)

Como vimos, o foco do design está passando para o "Sistema Produto-Serviço", isto é, projetar e avaliar o produto a partir da sua função(VEZZOLI, 2010), ou como meio para um fim (THACKARA, 2008). Logo, "o design rapidamente deixa de conceber apenas produtos de uso cotidiano e passa a incluir processos, sistemas e organizações" (NEUMEIER, 2010, p.13).

\section{CONSIDERAÇÕES FINAIS}

Em suma, a proposta conceitual de Gestão de Design para Sustentabilidade que incorpore conceitos e instrumentos da Política Nacional de Resíduos Sólidos foi elaborada com intuito de fornecer fundamentos para uma prática da Gestão de Design nas organizações que atuam no Brasil. Os três níveis da gestão de design - gestão operacional, gestão tática e gestão estratégica - podem ser encarados como uma escalada rumo a utilização do potencial do design pela empresa.

A aplicação da proposta elaborada de integração da Política Nacional de Resíduos Sólidos ao níveis de Gestão de Design pode iniciar com a gestão de um projeto de design que adote a perspectiva de projetar todo o ciclo de vida do sistema de produto-serviço, ou mesmo de gestão operacional de design de sistemas sustentáveis. Em seguida fomentando o nível tático de gestão de design, no caso, concebendo uma estrutura participativa para o design das inovações sustentáveis. Por fim, com a introdução da dimensão estratégica, que implica na gestão da própria empresa utilizando uma filosofia de design e, de acordo com o modelo, implicaria também na adoção do design sistêmico como filosofia na gestão empresarial e na incorporação do design para sustentabilidade na missão e nas estratégias da empresa.

Cabe ressaltar que esta se trata de uma proposta de integração entre Gestão de Design e a Política Nacional de Resíduos Sólidos. A consideramos válida por integrar correntes atuais dentro do design, que respondem a questões e desafios para o design, para as empresas e para a sociedade em todo o território nacional. Contudo, outros caminhos e possibilidades podem ser explorados e desenvolvidos em estudos futuros. 


\section{REFERÊNCIAS}

ANDRADE, Aurélio L. Pensamento Sistêmico: caderno de campo: o desafio da mudança sustentada nas organizações e na sociedade- Porto Alegre : Bookman, 2006 CPD, Manual de Gestão de Design. Centro Português de Design. Portugal, 1997.

DMI - Design Managment Institute. What is design management? Disponível em: <http://www.dmi.org/dmi/html/aboutdmi/design_management.htm>. Acessado em: 03 mai. 2014. Tradução livre do autor

ECHEVARRIA, Santiago Garcia; Prólogo in Estrategias de comunicación / Rafael Alberto Pérez, 3 ed.; Editora Ariel: Barcelona, 2006

GABEIRA, Fernando. Congresso e Meio Ambiente in Meio Ambiente no século 21: 21 especialistas falam da questão ambiental nas suas áreas de conhecimento/ coordenação André Trigueiro - Rio de Janeiro: Sextante, 2003.

GIL, A. C. Metodologia do ensino superior. 3. ed. São Paulo: Atlas, 1987.

KERZNER, Harold. Gestão de Projetos: as melhores práticas/ tradução Lene Belon Rlbeiro - 2ed. Porto Alegre : Bookman, 2006.

KRUCHEN, Lia, Design e Território: valorização de identidades e produtos locais. São Paulo, Studio Nobel, 2009.

MANZINI, Ezio; VEZZOLI, Carlo; O Desenvolvimento de Produtos Sustentáveis. tradução de Astrid de Carvalho. 1ed. São Paulo: Ed. Universidade de São Paulo, 2005.

MARTINS, Gilberto de Andrade; Manual para elaboração de monografias e dissertações / Gilberto de Andrade Martins. - 2. ed. - São Paulo : Atlas, 2000.

MAXIMIANO, Antonio César Amaru. Além da Hierarquia - Como implantar estratégiasparticipativas para administrar a empresa enxuta. São Paulo : Atlas, 1995.

MOZOTA, Brigitte. Gestão do design - usando o design para construir valor de marca e inovação corporativa; tradução Lene Belon Ribeiro ; revisão técnica: Gustavo Severo de Borba - Porto Alegre : Bookman, 2011.

NEUMEIR, Martin. A empresa orientada pelo design; tradução Felix José Nonenmacher - Porto Alegre : Bookman, 2010

PORTAS, Nuno; Design: política e formação in Design em aberto: uma antologia. Centro Português de Design, 1993.

SANOFF, Henry. Editorial in Design Studies, Volume 28, Issue 3 p-213-340. May 2007

STAMM, Bettina Von. Managing innovation, design and creativity. 2 ed. Chichester, UK : John Wiley \& Sons, Ltd. 2008

STRAIOTO, Ricardo G. T., FIGUEIREDO, Luiz F., Perspectivas para o Design Sustentável no Brasil a partir da nova Política Nacional de Resíduos Sólidos in. 3o Simpósio Brasileiro de Design Sustentável. 2011. Anais. Recife : Editora Universitária, 2011.p.795-806.

THACKARA, John. Plano B: o design e as alternativas viáveis em um mundo complexo tradução Cristina Yamagami - São Paulo : Saraiva : Versar, 2008.

VEZZOLI, Carlo. Design de Sistemas para a Sustentabilidade : teoria, métodos e ferramentas para o design sustentável de "sistemas de satisfação" / Carlo Vezzoli. Salvador : EDUFBA, 2010. 343p. 